\title{
Del Proyecto a la Acción: Historia de la creación y labor del Instituto de la Familia de la UNIFÉ
}

\author{
From the to Project to the Action: History of creation and labor of \\ UNIFE'S Family Institute
}

Gisela Vidal Cabeza de Tarazona*

\section{Resumen}

El presente artículo es el relato de la historia de la creación del Instituto de la Familia de la UNIFÉ, así como de las actividades y acciones tomadas en defensa de la vida, la persona, la familia y la mujer desde su creación hasta la actualidad.

\section{Palabras Clave}

Derechode Familia, Derecho de la persona, mujer, valores.

\begin{abstract}
This article develops the history of the creation of the Family Institute of UNIFE, as well as the activities and actions taken in defense of life, the individual, the family and women from its inception until today..
\end{abstract}

\section{Keywords}

Family Law, Law ofperson, woman, values.

\footnotetext{
* Abogada por la UNIFE. Con estudios de Maestria en Derecho de los Negocios - USMP; Conciliadora Extrajudicial. Asesora Legal de la Asociación Suzuki del Perú. Coordinadora Administrativa del Instituto de la Familia de la UNIFE. Fue integrante del Equipo Consultivo de la Comisión Revisora de la Ley frente a la Violencia Familiar del Congreso de la República.
}

Fecha de recepción: 25/07/2014

Fecha de aceptación: 20/08/2014 


\section{Introducción}

La familia de hoy no es la misma de hace 50 años atrás. Si bien vivimos en una época donde estamos concientizando a las nuevas generaciones sobre el derecho a la igualdad de oportunidades entre hombres y mujeres para vivir una vida de complementariedad, pues no podemos decir que estemos cumpliendo eficientemente como sociedad con aquel compromiso adquirido y que nos demanda la Declaración de los Derechos Humanos así como por nuestra Constitución Política del Perú, documentos jurídicos donde no solo comprometen al Estado peruano sino también a nosotros como sociedad: el de proteger a la familia, reconociéndola, además, como instituto natural y fundamental de la sociedad.

El incremento de procesos judiciales en materia de derecho de familia, el aumento de casos de femenicidio, de madres adolescentes, de violencia familiar, el aumento de la explotación niños y adolescentes mediante el trabajo infantil, el temor de muchas parejas al compromiso para la realización de un proyecto de vida en matrimonio, así como los problemas bioéticos que surgen por el avance tecnológico - donde el hombre es simplemente un medio para la obtención de un fin-, son sólo algunos ejemplos que nos muestran lo frágil y deteriorado que se encuentra la familia hoy en día. ¿Qué deparará a las futuras generaciones que no puedan formarse en un ambiente apropiado para su sano desarrollo como persona? ¿Dónde podrán las futuras generaciones adquirir un aprendizaje en valores, necesarios para poder dirigir su vida por un camino de bien? ¿Cómo aprenderán a comportarse como un buen padre o una buena madre, si no tuvieron la suerte de tener como buenos ejemplos a sus propios progenitores? ¿Por qué el interés de algunos de querer destruir o deformar a la familia?

¿Debemos hacer algo?, pues la repuesta es afirmativa y de suma urgencia. Creemos que no sólo el Estado debe asumir la responsabilidad de proponer y ejecutar las políticas públicas con la finalidad de encontrar la solución a todos estos problemas; sino también las universidades - como expresión misma de la sociedad,- deberán ejercer un papel primordial para contribuir al cambio de mentalidad, a la reeducación en valores y en la búsqueda de las soluciones a la problemática de la familia y la persona. En ese sentido, la Universidad Femenina del Sagrado Corazón, así como su Facultad de Derecho, conscientes de esta realidad en nuestra sociedad, ha hecho suyo su compromiso de contribuir, mediante iniciativas académicas en los campos jurídico e interdisciplinarios, al esclarecimiento y solución de la problemática 
de la familia y al fortalecimiento del matrimonio, promoviendo los valores individuales y sociales de la persona, la institución de la familia, la defensa de la vida y la persona, mediante la creación del Instituto de la Familia de la UNIFÉ.

En ese sentido, en el presente artículo, pasaremos a relatar las principales actividades y acciones realizadas por el Instituto de la Familia desde sus primeros años de creación hasta la actualidad.

\section{Del Proyecto a la Acción}

El proyecto de creación del Instituto de la Familia ${ }^{1}$ fue estudiado y elaborado por las autoridades y una comisión de docentes especialistas de la Facultad de Derecho.

Dicho proyecto señalaba en sus Antecedentes que desde sus inicios la Comisión Organizadora de la Facultad de Derecho consideró atender prioritariamente el tema de la Familia, decidiendo que debería enfatizarse su tratamiento especializado, así como otras Facultades de Derecho de otras universidades se habían orientado al campo penal, contractual o empresarial. Es así que, la currícula de estudios de la Facultad de Derecho de la UNIFE, sin descuidar la formación integral de las alumnas, presta especial atención, entre otras especialidades, al Derecho de Familia, incluyendo cursos, para su mejor estudio como Derecho Procesal Familiar, Derechos de los Niños, Niñas y Adolescentes, Violencia Familiar, Derecho Familiar Comparado y Derechos de la Mujer; siendo además, el tema de la mujer, la persona y la familia uno de sus líneas de investigación a nivel institucional.

Señalaba el proyecto, a su vez, que la creación del Instituto de la Familia ya se había programado en los Planes de Funcionamiento de la Facultadaprobados debidamente en su oportunidad por Asamblea Universitaria desde el año 1996, teniendo como principales objetivos, la investigación y el estudio de la familia peruana, la defensa de la familia y la realización de actividades dirigidas a la formación de la familia en el país.

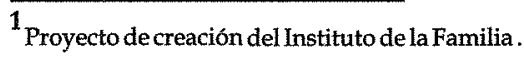


La orientación y preocupación de la Facultad de Derecho por el Derecho de Familia se evidenció, a su vez, con la creación en el año 2000, de la primera Maestría en Derecho Civil con mención en Familia en el Perú; Maestría que a la fecha cuenta ya con 14 promociones y cuyo Coordinador actual es el Dr. Luis Felipe Bramont - Arias Torres. Del mismo modo, durante varios años anteriores a la creación del Instituto de la Familia, diversos docentes de la Facultad de Derecho remitieron al Congreso de la República cometarios y propuestas sobre diversos proyectos de ley; como por ejemplo, el proyecto de ley que pretendía incorporar la separación de hecho como causal de divorcio invocable por cualquiera de los cónyuges. Asimismo, a través de los diversos medios de comunicación, (diarios, revistas, canales de televisión y emisoras radiales), la Facultad ha reiterado, por intermedio de sus autoridades y docentes, su compromiso y preocupación respecto al tema de la Familia.

El proyecto de creación del Instituto de la Familia mencionaba 7 objetivos los mismos que se centralizaban en:

a) la promoción y fortalecimiento de los valores de la persona y los que sustentan a la familia y el matrimonio; b) la investigación y estudio de la realidad familiar peruana así como su estudio desde una aproximación interdisciplinaria; c) el desarrollo de programas de orientación familiar; d) el fomento, organización y realización de eventos sobre la realidad familiar, conyugal y temas afines; e) la colaboración y asesoramiento a personas naturales o jurídicas y a otros grupos sociales cuya finalidad es la protección de la familia y el matrimonio.

En cuanto a las Áreas de actividad del Instituto de la Familia, el proyecto contemplaba las siguientes: a) Orientación y Promoción axiológica de la familia: b) Investigación; c) Docencia; d) Difusión; e) Servicio de Asesoramiento y Colaboración.

Una vez culminado la redacción del proyecto, la Dra. Gabriela Araníbar Fernández Dávila, en su condición de Decana de la Facultad de Derecho, sustentó ante el Consejo Universitario el Proyecto de creación del Instituto de la Familia, mereciendo la aprobación unánime de su creación por dicho órgano universitario en su sesión $\mathrm{N}^{\circ} 541$, del 14 de junio del año 2000.

Posteriormente, mediante Resolución Rectoral $\mathrm{N}^{\circ} 105-2000-\mathrm{CU}, \mathrm{y}$ estando a lo acordado por el Consejo Universitario en su sesión No. 541, considerando que "... la Universidad Femenina del Sagrado Corazón, en concordancia con los fines y principios que la orientan tiene sumo interés en la 
creación del Instituto de la Familia como respuesta a su compromiso con la sociedad, con la persona humana y la defensa de los valores fundamentales de la familia y de la unión conyugal", resolvió aprobar su creación, cuyo tenor literal es el siguiente:

\title{
"RESOLUCIÓNRECTORALN"105-2000-CU (...)
}

\section{RESUELVE:}

Artículo $1^{\circ}$ : Aprobar la creación del INSTITUTO de la FAMILIA, cuyo proyecto ha sido elaborado por la Facultad de Derecho de la UNIFÉ.

Artículo $2^{\circ}$ : Felicitar a las autoridades y docentes de la Facultad de Derecho, quienes participaron en la elaboración del citado Proyecto

Artículo 3: Elevar el correspondiente acuerdo a la Asamblea Universitaria para su ratificación.

Dada en Lima, a los catorce días del mes dejunio del dos mil.

\section{REGISTRESE, COMUINÍQUESE Y ARCHÍVESE ELGA GARÍCA ASTE, rscj RECTORA"}

$\mathrm{Al}$ año siguiente, el del 24 de febrero de 2001, la Asamblea Universitaria Extraordinaria ratificó por unanimidad el acuerdo tomado en Consejo Universitario en sesión ordinaria $N^{\circ} 541$ del 14 de junio del año 2000, bajo el siguiente tenor :

\begin{abstract}
"Aprobar la Creación del Instituto de la Familia, cuyo proyecto ha sido elaborado por la Facultad de Derecho de la UNIFÉ. Asimismo, acordó felicitar a las autoridades y docentes de la Facultad de Derecho, quienes participaron en la elaboración del citado Proyecto".
\end{abstract}

La Hna. Rectora Elga García Aste, expresó en dicha acta de reunión, la felicitación y el agrado de los directivos de la UNIFÉ por la creación del Instituto de la Familia, por la trascendencia que hoy más que nunca significa para el fortalecimiento de la familia. Pidió a la entonces Decana de la Facultad de Derecho, Dra Gabriela Araníbar Fernández Dávila, que confíe en el apoyo que va a tener de todos los directivos y personal de la UNIFÉ y destacó que el 
Instituto de la Familia respondía al pensamiento de Santa Magdalena Sofía, quien al fundar la Congregación del Sagrado Corazón, marcó especialmente la importancia de trabajar por la promoción de la familia cristiana.

La Dra. Gabriela Araníbar, por su parte, agradeció a nombre de la Facultad de Derecho por las palabras de la Hna. Rectora y por el apoyo que recibiría para el Instituto de la Familia, reiterando el compromiso de trabajar porque se haga realidad los fines y objetivos del Instituto.

Con la aprobación del proyecto que creaba el Instituto de la Familia por los órganos máximos de la UNIFÉ, se empezaron a dar las primeras actividades continuadas a lo largo de estos últimos 14 años, en beneficio de la comunidad universitaria y de la sociedad peruana en general; los cuales podemos resumir en los siguientes:

\subsection{Publicación de boletines}

En cumplimiento de sus fines de investigación y difusión, el Instituto de la Familia publicó por primera vez en el año 2005 el primer número de su Boletin, cuyo contenido puso a conocimiento de la Comunidad Universitaria de la UNIFÉ, la aprobación de la creación del Instituto de la Familia, así como también sus fines, áreas y los miembros que en aquel entonces lo conformaban, los docentes de la Facultad de Derecho: Luis Felipe Almenara Bryson (Decano) Gabriela Araníbar Fernández Dávila, Olga María Castro Pérez-Treviño, Myriam Falla Guirao, y Patrick Wagner Grau. De aquel primer Boletín impreso en el año 2005, al año 2010, podemos decir que tuvo una gran evolución. Fueron cinco años que, de manera ininterrumpida, el Instituto publicó y difundió sus actividades, proyectos y sobre todo, en sus últimos números, la publicación de artículos de opinión y de investigación de los miembros del Consejo Asesor del Instituto de la Familia, así como de especialistas de diversas profesiones invitados a escribir sobre temas de persona, valores, mujer y familia. Debemos señalar que esta gran labor estuvo a cargo de la Docente Dra. Miryam Falla Guirao de Güich, como editora y Coordinadora del Área de Orientación y Promoción Axiológica de la Familia y Difusión del Instituto, y siempre con el apoyo de la Coordinadora del Instituto de la Familia.

A continuación, hacemos un recuento de los artículos publicados en los últimos números del Boletín del Instituto: 
BOLETIN No 07 (Año 2009)

\begin{tabular}{|l|l|}
\hline Autor(a) & Título del artículo \\
\hline Gisela Vidal Cabeza & $\begin{array}{l}\text { Día Internacional de la no violencia contra la } \\
\text { mujer. El Dia de la Mariposas..." / "Día } \\
\text { Internacional de los impedidos "una sociedad } \\
\text { para todos. }\end{array}$ \\
\hline $\begin{array}{l}\text { Rossina Rojas Vidal (estudiante del XI } \\
\text { ciclo de al Facultad de Derecho) }\end{array}$ & $\begin{array}{l}\text { Violencia contra la mujer un problema complejo y } \\
\text { multidimensional. }\end{array}$ \\
\hline
\end{tabular}

\section{BOLETIN Nº 08 (Año 2009)}

\begin{tabular}{|l|l|}
\hline Autor(a) & Título del artículo \\
\hline Olga María Castro Pérez- Treviño & $\begin{array}{l}\text { El Derecho a la intimidad A propósito de la Ley No } \\
29032 \text { que exige la expedición de una nueva } \\
\text { Partida o Acta de Nacimiento por reconocimiento } \\
\text { posterior a la inscripción. }\end{array}$ \\
\hline $\begin{array}{l}\text { Romina Herrera Fiestas (estudiante del } \\
\text { IX ciclo - Facultad de Derecho) }\end{array}$ & $\begin{array}{l}\text { Convención Interamericana para prevenir } \\
\text { sancionar y erradicar la Violencia contra la mujer } \\
\text { "Convención de Belém do Pará". }\end{array}$ \\
\hline
\end{tabular}

\section{BOLETIN Nº 09 (Año 2009)}

\begin{tabular}{|l|l|}
\hline Autor(a) & Título del artículo \\
\hline Myriam Falla Guirao de Güich & ¿Cómo internalizar valores? \\
\hline
\end{tabular}

\section{BOLETIN No 10 (Año 2009)}

\begin{tabular}{|l|l|}
\hline Autor(a) & Título del artículo \\
\hline Myriam Falla Guirao de Güich & La familia como ente educador de la persona. \\
\hline $\begin{array}{l}\text { Maria Dolores Vilacoro (Directora de la } \\
\text { Cátedra de Bioética y Biojuridica de la } \\
\text { UNESCO) }\end{array}$ & El Aborto es un Delito. \\
\hline Sylvia Torres Morales de Ferreyros & La lglesia y la Eutanasia. \\
\hline Olga María Castro Pérez-Treviño & La Familia Hoy. \\
\hline
\end{tabular}

\section{BOLETIN N 11 (Año 2009)}

\begin{tabular}{|l|l|}
\hline Autor(a) & Título del articulo \\
\hline Fernando Arias - Stella Castillo & El matrimonio putativo. \\
\hline Ronald Cárdenas Krenz: & Educación, Bioética y valores. \\
\hline Miryam Falla de Güich: & Del DNI al DNA \\
\hline Ricardo Valverde Morante & $\begin{array}{l}\text { Filliación por reproducción médicamente asistida : } \\
\text { "Embarazo Post Mortem". }\end{array}$ \\
\hline Patricia Beltrán Pacheco & $\begin{array}{l}\text { El mejor padre son ambos padres ies viable la } \\
\text { tenencia compartida en el Perú? }\end{array}$ \\
\hline $\begin{array}{l}\text { Fernando Gamarra Rubio y Milagros } \\
\text { Escribens Coello: }\end{array}$ & Tenencia compartida: inviabilidad. \\
\hline
\end{tabular}


BOLETIN Nº 12 (Año 2010)

\begin{tabular}{|c|c|}
\hline Autor(a) & Título del artículo \\
\hline Benjamín Aguilar Llanos & $\begin{array}{l}\text { Apreciación crítica de la Ley } 29486 \text { sobre el } \\
\text { instituto juridico de los alimentos. }\end{array}$ \\
\hline Olga María Castro Pérez-Treviño & $\begin{array}{l}\text { La Convención sobre los Derechos del niño, } \\
\text { presente en nuestro Código de los Niños y } \\
\text { Adolescentes. }\end{array}$ \\
\hline Amaro La Rosa Pinedo & $\begin{array}{l}\text { La Violencia en los medios y su influencia en la } \\
\text { conducta de los adolescentes. }\end{array}$ \\
\hline María Teresa Cabrera de la Cruz & Apuntes sobre la violencia familiar en el Perú. \\
\hline Orfelinda Garcia Camacho & $\begin{array}{l}\text { Intervención interdisciplinaria en un caso de } \\
\text { maltrato infanti". }\end{array}$ \\
\hline Rocio Guardamano Revolledo & La Violencia Familiar. \\
\hline José Guerrero La Rosa & Agresión Electrónica. \\
\hline Erika ramos Amao & Ellos también sufren en silencio. \\
\hline Enma Romero Ysusqui & $\begin{array}{l}\text { ¿La violencia familiar es una expresión de la } \\
\text { crisis de la familia en el Perú? }\end{array}$ \\
\hline Marilú Valdivia & $\begin{array}{l}\text { Trabajo en prevención: talleres para padres y } \\
\text { alumnos. }\end{array}$ \\
\hline
\end{tabular}

Debemos mencionar que, a partir del año 2008 el Boletín adquirió propiamente la forma de una publicación mucho más formal, tipo revista, gracias al apoyo incondicional de la Facultad de Derecho para la publicación de los Boletines. Estas publicaciones han sido remitidas a entidades públicas y privadas, recibiendo respuestas de agradecimiento y felicitación de diversas entidades y personalidades como el Nuncio Apostólico en el Perú, Mons Bruno Musaró.

\subsection{Revista persona y familia}

En el año 2011, el Mg. Manuel Rivera Parreño, quien fuera Decano de la Facultad de Derecho, en sesión del Consejo Asesor, sugirió convertir el Boletín del Instituto en una Revista, que cumpliera con las exigencias internacionales para la publicación de artículos, y también para su indización.

Es así, que desde el año 2012, el Instituto asumió la tarea de elaborar su Revista denominada "Persona y Familia", como un medio a través del cual los docentes de la UNIFÉ, así como especialistas de otras instituciones tanto 
públicas como privadas, puedan publicar sus investigaciones realizadas en el campo de los derechos de las personas, la mujer, la familia, los valores, así como la Bioética y la Biojurídica. La Revista "Persona y Familia" del Instituto de la Familia, convoca cada año la presentación de artículos, los cuales son revisados previamente para determinar el cumplimiento de las formalidades necesarias para la publicación de artículos, así como los requisitos para la indexación internacional. A continuación, ofrecemos un listado de docentes e investigadores que han colaborado con sus artículos en estos últimos años:

REVISTA PERSONA Y FAMILIA Nº 01 (Año 2012)

\begin{tabular}{|l|l|}
\hline Autor (a) & Título del artículo \\
\hline Benjamín Aguilar Llanos & El Consejo de Familia. \\
\hline Fernando Arias - Stella Castillo & $\begin{array}{l}\text { La intervención concurrente del cónyuge } \\
\text { como requisito de eficacia del acto } \\
\text { jurídico según el artículo } 315 \text { del Código } \\
\text { Civil Peruano. }\end{array}$ \\
\hline Sabina Deza Villanueva & $\begin{array}{l}\text { Pautas para la atención de mujeres } \\
\text { victimas de violencia familiar. }\end{array}$ \\
\hline María Isabel Sokolich Alva & $\begin{array}{l}\text { Reflexiones sobre el tratamiento de la } \\
\text { filiación en el Perú. }\end{array}$ \\
\hline Oscar Zegarra Guzmán & $\begin{array}{l}\text { El Proceso de Separación Convencional } \\
\text { Notarial y Municipal. }\end{array}$ \\
\hline
\end{tabular}

REVISTA PERSONA Y FAMILIA Nº 02 (Año 2013)

\begin{tabular}{|c|c|}
\hline Autor(a) & Título del artículo \\
\hline Ronald Cárdenas Krenz & $\begin{array}{l}\text { Dos interesantes sentencias a propósito } \\
\text { de la posibilidad de patentar embriones y } \\
\text { genes. }\end{array}$ \\
\hline Mario Castillo Freyre & La sucesión en las uniones de hecho. \\
\hline Maria Teresa Comejo Fava & $\begin{array}{l}\text { La naturaleza juridica de la unión de } \\
\text { hecho a la luz de la ley } 30007 \text {. }\end{array}$ \\
\hline Nita Gamio de Barrenechea & La mujer profesional en la familia. \\
\hline Percy Huaroc Llaja & $\begin{array}{l}\text { Y... ¿dónde quedan los niños?... La otra } \\
\text { cara del femenicidio. }\end{array}$ \\
\hline Graciela Medina (Argentina) & $\begin{array}{l}\text { Las grandes reformas al derecho de } \\
\text { familia en el proyecto del Codigo Civil } \\
\text { argentino 2012. }\end{array}$ \\
\hline Carmen Beatriz Velazco Ramos & $\begin{array}{l}\text { ¿Comprende usted lo que significa } \\
\text { abortar?. Una aproximación a los } \\
\text { requerimientos de la información } \\
\text { regulados en la Women's Right to know } \\
\text { act. }\end{array}$ \\
\hline
\end{tabular}


REVISTA PERSONA Y FAMILIA N 3 (Año 2014)

\begin{tabular}{|l|l|}
\hline Autor(a) & Título del artículo \\
\hline Ronald Cárdenas Krenz & $\begin{array}{l}\text { Consideraciones jurídicas en torno a la } \\
\text { ovodonación. }\end{array}$ \\
\hline María Teresa Cornejo Fava & $\begin{array}{l}\text { La separación de hecho de los cónyuges } \\
\text { como causa de la separación de cuerpos } \\
\text { y del divorcio: Peculiaridades. }\end{array}$ \\
\hline Cecilia Gabriela González Fuentes & $\begin{array}{l}\text { Los medios de comunicación en el Perú } \\
\text { y la tendencia Global. A propósito del } \\
\text { ensayo la Civilización del Espectáculo. }\end{array}$ \\
\hline Luis Enrique Pazos Maldonado & $\begin{array}{l}\text { La mendicidade de los niños, niñas y } \\
\text { adolescentes en el Perú. }\end{array}$ \\
\hline Karen Maribel Rebaza Vilchez & $\begin{array}{l}\text { Inocencia interrumpida: La protección de } \\
\text { los Derechos fundamentales de los niños } \\
\text { yadolescentes a propósito del caso } \\
\text { VRAEM. }\end{array}$ \\
\hline Gisela Hortencia Vidal Cabeza & $\begin{array}{l}\text { Del proyecto a la acción: Historia de la } \\
\text { creacióny labor del Instituto de la Familia de } \\
\text { la UNIFÉ }\end{array}$ \\
\hline
\end{tabular}

\subsection{Conferencias organizadas por el instituto de la familia:}

El compromiso del Instituto de la Familia y de la Facultad de Derecho de la UNIFÉ en la formación de sus estudiantes, así como el interés de informar a la Comunidad Universitaria en general, sobre temas coyunturales en el campo de las personas y la familia, ha propiciado desde hace varios años la realización de conferencias gratuitas, las mismas que se llevan a cabo los días jueves al mediodía en la Sala de Conferencias de la Biblioteca de la UNIFÉ. A continuación, mencionamos las conferencias realizadas y que fueron dictadas a cargo de nuestros docentes, miembros del Instituto de la Familia e invitados nacionales como internacionales, en los últimos años:

\section{3 (Año 2014)}

\begin{tabular}{|l|l|}
\hline Tema de la Mesa Redonda & \multicolumn{1}{c|}{ Conferencistas } \\
\hline $\begin{array}{l}\text { "El origen de la Vida y el fin de la vida } \\
\text { humana" }\end{array}$ & $\begin{array}{l}\text { Ronald Cárdenas Krenz } \\
\text { Sylvia Torres Morales de Ferreyros } \\
\text { Patrick Wagner Grau }\end{array}$ \\
\hline
\end{tabular}




\section{Año 2007}

\begin{tabular}{|l|l|}
\hline Tema de Conferencia & Conferencista \\
\hline $\begin{array}{l}\text { "Diálogos Axiológicos". (Dirigido a las estudiantes de la } \\
\text { Facultad de Derecho y de otras Facultades). }\end{array}$ & $\begin{array}{l}\text { Dra. Gabriela Aranibar Fernández } \\
\text { Dávila y Dra Nita Gamio de } \\
\text { Barrenechea }\end{array}$ \\
\hline $\begin{array}{l}\text { "Tratamiento de la Adopción de Menores en nuestro } \\
\text { país". }\end{array}$ & $\begin{array}{l}\text { Dr. César Díaz Palao (Ex Secretario } \\
\text { Técnico de la Oficina de Adopciones del } \\
\text { MIMDES) }\end{array}$ \\
\hline "Principios y bases para el Bienestar familiar". & Fátima Castro Avilés \\
\hline $\begin{array}{l}\text { "El Derecho a la identidad a Propósito de la dación } \\
\text { nueva partida de nacimiento por reconocimiento } \\
\text { posterior a la inscripción." }\end{array}$ & Olga Maria Castro Pérez-Treviño. \\
\hline "Eutanasia y Derecho". & Sylvia Torres Morales de Ferreyros \\
\hline
\end{tabular}

Año 2007

\begin{tabular}{|c|c|}
\hline Tema de Conferencia & Conferencista \\
\hline $\begin{array}{l}\text { Panel Avances en Investigación Jurídica } \\
\text { (Dar a conocer a la comunidad universitaria los resultados } \\
\text { de diversos trabajos de investigación concluidos en los } \\
\text { últimos meses). }\end{array}$ & Miembros del Consejo Asesor \\
\hline $\begin{array}{l}\text { "Un nuevo rostro para el adulto mayor: El respeto de } \\
\text { sus derechos fundamentales". }\end{array}$ & Olga María Castro Pérez-Treviño \\
\hline $\begin{array}{l}\text { "Análisis de la nomativa relativa al nombre y a la } \\
\text { filiación, contenida en el Código Civil y su incidencia } \\
\text { en el Derecho a la identidad de la persona". }\end{array}$ & María Teresa Cornejo Fava \\
\hline $\begin{array}{l}\text { "La Persona, un desafio ontológico para la Bioética" } \\
\text { "Colisión de Derechos: Un caso a considerar a } \\
\text { propósito de las acciones del Estado frente a la } \\
\text { lucha contra la pornografia infantil". }\end{array}$ & $\begin{array}{l}\text { Myriam Falla de Güich } \\
\text { Sylvia Torres Morales de Ferreyros }\end{array}$ \\
\hline
\end{tabular}

\section{Año 2008}

\begin{tabular}{|l|l|}
\hline Tema de Conferencia & Conferencista \\
\hline $\begin{array}{l}\text { "Ciencia y Fe ise oponen o se } \\
\text { complementan?" }\end{array}$ & Patrick Wagner Grau \\
\hline $\begin{array}{l}\text { "Aspectos resaltantes del Proyecto de } \\
\text { modificación al Código de los Niños y } \\
\text { Adolescentes". }\end{array}$ & Silvana Gabrieli (asesora del MINJUS) \\
\hline $\begin{array}{l}\text { "Ley de igualdad de oportunidades entre } \\
\text { el varón y la mujer "y "Hostigamiento } \\
\text { Sexual". }\end{array}$ & $\begin{array}{l}\text { Eugenia Fernan Zegarra (funcionaria de la } \\
\text { Defensoria del Pueblo) }\end{array}$ \\
\hline "Nuevos pecados Capitales: Visión actual " & Patrick Wagner Grau \\
\hline $\begin{array}{l}\text { "Violencia Familiar. Una propuesta de } \\
\text { reforma legislativa". }\end{array}$ & Olga María Castro Pérez - Treviño \\
\hline
\end{tabular}


Año 2009:

\begin{tabular}{|l|l|}
\hline $\begin{array}{l}\text { Tema de Conferencia } \\
\text { "Valores éticos en el matrimonio y en la } \\
\text { familia". }\end{array}$ & Myriam Falia Guirao de Güich \\
\hline $\begin{array}{l}\text { "Derecho y uso de las células madre: } \\
\text { Reto para la Etica." }\end{array}$ & Patrick Wagner Grau \\
\hline $\begin{array}{l}\text { Panel sobre: "Hábitos de salud de las } \\
\text { estudiantes". }\end{array}$ & $\begin{array}{l}\text { El evento fue la exposición de los resultados de } \\
\text { las encuestas sobre hábitos de salud entre las } \\
\text { estudiantes de Derecho organizado por la } \\
\text { Facultad de Derecho como parte de las } \\
\text { actividades del Instituto de al Familia y de la } \\
\text { Cátedra de Bioética y Biojuridica. Participaron } \\
\text { una educadora, una psicóloga y un abogado. } \\
\text { Patricia Melloh Navarro (Educadora) } \\
\text { Gabriela Perotti (Psicóloga) y Oscar Zegarra } \\
\text { Guzmán (abogado) }\end{array}$ \\
\hline
\end{tabular}

Año 2010

\begin{tabular}{|l|l|}
\hline Tema de Conferencia & Conferencista \\
\hline $\begin{array}{l}\text { "Reflexiones sobre la Ley que prueba el } \\
\text { sexrimonio de las personas del mismo } \\
\text { sexoentina" }\end{array}$ & Octavio Lo Prete (Argentina) \\
\hline $\begin{array}{l}\text { "¿Puede cuestionarse legalmente el uso } \\
\text { de simbolos religiosos en el ámbito } \\
\text { politico?", }\end{array}$ & Javier García Oliva (España) \\
\hline $\begin{array}{l}\text { Mesa Redonda "La Pedofilia: ¿Por qué } \\
\text { se da y cómo tratarla? Una explicación } \\
\text { médica, psicológica y legal". }\end{array}$ & Patrick Wagner, Luis Felipe Bramont Arias \\
\hline
\end{tabular}

Año 2011

\begin{tabular}{|l|l|}
\hline Tema de Conferencia & Conferencista \\
\hline "Principales normas legales que & A cargo de funcionarios del CONADIS. \\
favorecen a las personas con & Sandra Piro Marcos \\
discapacidad" y "La educación inclusiva & María Luisa Castañeda Espinoza \\
como derecho", & \\
\hline
\end{tabular}

Año 2012

\begin{tabular}{|l|l|}
\hline Tema de Conferencia & Conferencista \\
\hline $\begin{array}{l}\text { ¿Deben tener más derechos } \\
\text { laniones de hecho? }\end{array}$ & $\begin{array}{l}\text { Nita Gamio y Maria Teresa Cornejo Fava, } \\
\text { dirigidos a las estudiantes de la Facultad de } \\
\text { Derecho. }\end{array}$ \\
\hline
\end{tabular}

\section{Año 2014}

\begin{tabular}{|l|l|}
\hline Tema de Conferencia & Conferencista \\
\hline $\begin{array}{l}\text { "Análisis de la Jurisprudencia de la } \\
\text { Corte Superior en materia de Violencia } \\
\text { Familia" }\end{array}$ & $\begin{array}{l}\text { Luz Maria Capuña y Chavez - Presidenta de } \\
\text { la Primera Sala Especializada de Familia }\end{array}$ \\
\hline $\begin{array}{l}\text { PERSONA Y FAMILIA No } 03 \text { 2014 } \\
\text { Revista del Instituto de la Familia } \\
\text { Facultad de Derecho }\end{array}$ & $\underline{\mathbf{9 4}}$ \\
\hline
\end{tabular}




\subsection{Eventos académicos realizados}

Dentro de las actividades propias del Instituto de la Familia está la de docencia, la misma que se viene desarrollando hasta la actualidad habiendo capacitado a través de cursos, seminarios, jornadas y diplomados cerca de 600 personas entre estudiantes de pre y post grado de la UNFÉ, así como público en general, en estos últimos años:

\begin{tabular}{|c|c|c|}
\hline ANO & EVENTO & DURACIÓN \\
\hline 2003 & Fórum: "Maltrato Infantil" & $\begin{array}{l}\text { Del } 10 \text { al } 12 \text { de noviembre } \\
\text { de } 2003\end{array}$ \\
\hline 2007 & $\begin{array}{l}\text { Diplomado: "Aproximación interdisciplinaria del } \\
\text { Derecho de Familia y Derecho de los Niños, Niñas } \\
\text { y Adolescentes" }\end{array}$ & $\begin{array}{l}\text { Del } 27 \text { de marzo al } 22 \text { de } \\
\text { noviembre de } 2007 \text { ( } 8 \\
\text { meses). }\end{array}$ \\
\hline \multirow[t]{2}{*}{2009} & $\begin{array}{l}\text { II Curso de Especialización : "El Sistema de } \\
\text { Adopciones en el Perú" } \\
\text { (Evento en el que participaron como plana docente } \\
\text { funcionarios de la Secretaría Nacional de Adopciones) }\end{array}$ & $\begin{array}{l}\text { Del } 15 \text { de agosto al } 26 \text { de } \\
\text { septiembre (sólo sábados). }\end{array}$ \\
\hline & $\begin{array}{l}\text { Curso de Especialización: "La Violencia Familiar } \\
\text { desde una Perspectiva interdisciplinaria" }\end{array}$ & $\begin{array}{l}\text { Del } 2 \text { de octubre hasta el } \\
11 \text { de diciembre de } 2009\end{array}$ \\
\hline 2010 & $\begin{array}{l}\text { III Curso Especializado: "El Sistema de } \\
\text { Adopciones en el Perú". } \\
\text { (Evento en el que participaron como plana docente } \\
\text { funcionarios de la Secretaría Nacional de Adopciones) }\end{array}$ & $\begin{array}{l}\text { Del } 22 \text { de mayo al } 10 \text { de } \\
\text { julio del año } 2010 \\
\text { (sábados) }\end{array}$ \\
\hline $\begin{array}{l}2010- \\
2011\end{array}$ & $\begin{array}{l}\text { Curso Especializado en Derecho Procesal } \\
\text { Familiar }(2010-2011)\end{array}$ & $\begin{array}{l}\text { Del } 05 \text { de noviembre de } \\
2010 \text { al } 28 \text { de enero de } \\
2011 \text { (viernes) }\end{array}$ \\
\hline 2013 & $\begin{array}{l}\text { Seminario Especializado: }{ }^{2} \text { Adolescentes } \\
\text { infractores de la Ley Penal: Análisis y } \\
\text { Perspectivas }\end{array}$ & $\begin{array}{l}\text { Días jueves } 22 \text { y viernes } \\
23 \text { de noviembre de } 2012 \text {, }\end{array}$ \\
\hline 2014 & $\begin{array}{l}\text { Jomadas por los } 30 \text { Años del Código Civil: } \\
\text { Persona y Familia } \\
\text { (Evento realizado en coorganización con el Ministerio de } \\
\text { Justicia y Derechos Humanos) }\end{array}$ & $\begin{array}{l}4 \text { y } 5 \text { de noviembre de } \\
2014\end{array}$ \\
\hline
\end{tabular}

\subsection{Pronunciamientos y documentos publicados}

Como es de público conocimiento, nuestra sociedad ha atravesado momentos en los que los valores, la persona y la familia se han visto amenazados. En tal sentido, el Instituto de la Familia se ha pronunciado oportunamente a través de los medios de prensa, así como también ha contribuido con las opiniones de especialistas para la mejor dación de leyes 
que lo regulen. A continuación, mencionaremos una relación de los pronunciamientos e informes sobre Proyectos de leyes presentados ante el Congreso de la República:

1. Pronunciamiento: En defensa de la dignidad del ser humano y la familia . Publicado el 11 de mayo de 2008 en el Diario El Comercio.

2. Pronunciamiento: En defensa de la Vida, publicado el 18 de octubre de 2009 en el Diario El Comercio Sección A-11.

3. Documento: Consideraciones con relación a al aplicación de la Ley 29227-Recomendaciones efectuadas por el Consejo Asesor del Instituto de la Familia de al UNIFÉ para ser incorporadas en el Reglamento de la Ley 29227.

4. Proyecto de Ley de Prevención y protección frente a la violencia familiar que afecta a mujeres y niños principalmente (modificaciones al Texto Único Ordenado de la Ley de protección frente a la Violencia familiar aprobado por Decreto Supremo $N^{\circ}$ 006-97-JUS). Es el aporte de un grupo d e estudiantes del "Diplomado en Derecho de Familia, Derecho de los niños, niñas y adolescentes: Una aproximación interdisciplinaria", que organizó el Instituto de la Familia en el año 2007. El mencionado Proyecto fue presentado al Ministerio de Justicia y su elaboración estuvo a cargo de la Abog. Silvana Gabrieli Arienzo bajo la orientación de la Abog. Olga María Castro Pérez Treviño.

5. Documento: "Aportes del Instituto de la Familia de la Facultad de Derecho de la UNIFÉ para la Reforma de la Ley contra la Violencia Familiar", elaborado por la Dra Patricia Beltrán docente del área de Derecho de la Familia de la Facultad de Derecho de la UNIFÉ, a quien el Consejo Asesor del Instituto de la Familia le encargó, en su calidad de docente investigadora del Instituto de la Familia. Este documento fue presentado a la Comisión Revisora de al Ley de Protección frente a la Violencia Familiar del Congreso de la República como un aporte de la UNIFÉ para la elaboración de una nueva ley contra la violencia familiar.

6. Documento: Comentarios sobre el Proyecto de Ley que simplifica el Proceso de alimentos y regula la aplicación del Principio de Oralidad. Elaborado por Olga María Castro y presentado a la Comisión de Justicia y Derechos Humanos del Congreso de la República, en relación al Proyecto de Ley que simplifica el proceso de alimentos y regula la 
aplicación del Principio de Oralidad, cuyo texto se encontraba en dicha Comisión en el Congreso.

7. Elaboración de informes por los miembros del Consejo Asesor del Instituto de la Familia conteniendo la opinión del Instituto de la Familia de la Facultad de Derecho de la UNIFÉ con relación a los Proyectos de Ley remitidos por la Comisión de la Mujer y Familia del Congreso de la República:

- Informe sobre el Proyecto de Ley No 3234/2013-CR . Proyecto de Ley que modifica la Ley No 29174 "Ley General de Centros de Atención Residencial de niñas, niños y adolescentes"

- Informe sobre el Proyecto de Ley No 3260/2013-CR : Proyecto de Ley que modifica el artículo $6^{\circ}$ de la Ley 27337 "Código de niños y adolescentes sobre la protección a la identidad del menor infractor de la ley penal".

- Informe sobre el Proyecto de Ley No 3213/2013-CR: Proyecto que modifica el artículo $23^{\circ}$ del Código de los Niños y Adolescentes, incorporando los Derechos del Niño Hospitalizado.

- Informe sobre el Proyecto de Ley No 3296/2013-CR "Ley que incorpora requisitos para el procedimiento de adopción de niñas, niños y adolescentes declarados judicialmente en estado de abandono".

- Informe sobre el Proyecto de Ley No 3313/2013-CR "Ley que establece causales que limitan la patria potestad por la comisión del delito de feminicidio tipificado en el artículo 108-B del Código Penal".

\subsection{Participación de docentes en eventos representando a la UNIFÉ y al Instituto de la Familia}

Los miembros integrantes del Consejo Asesor del Instituto de la Familia, han participado, a su vez, en diversos eventos organizados por otras entidades nacionales como extranjeras en representación del Instituto de la Familia y de la Facultad de Derecho de la UNIFÉ, como el Congreso de la República, la Academia Nacional de Medicina, el Colegio de Abogados de 
Lima, el Ministerio de Justicia y Derechos Humanos, Ministerio de la Mujer y Poblaciones Vulnerables, Municipalidades, en el VI y VII Congreso Latinoamericano del Caribe de Bioética (Argentina) entre otros.

\section{Los responsables de esta noble acción: Miembros que conformaron y conforman el Instituto de la Familia}

Es importante señalar que toda la actividad desarrollada por el Instituto de la Familia en los últimos años, se debe al trabajo y dedicación de los miembros del Consejo Asesor del Instituto de la Familia conformado por docentes de la UNIFÉ con el apoyo de la Facultad de Derecho. La especialidad de cada uno de ellos es diversa, por lo que una de las características de este Consejo es que es multidisciplinario, condición adecuada para poder realizar un mejor estudio de la problemática de la familia, la mujer y la persona.

Para la marcha del Instituto, desde su creación, el Consejo Asesor se reúne mensualmente, así como también organiza reuniones de trabajo.

A continuación, mencionamos la relación de docentes que conformaron y conforman actualmente el Consejo Asesor del Instituto de la Familia:

- Gabriela Araníbar Fernández-Dávila, Abogada, past Decana de la Facultad de Derecho, especialista en Derecho de la Mujer, miembro fundadora, laboró en el Instituto hasta el 07 de mayo de 2010, fecha en que falleció.

- Myriam Falla Guirao, Filósofa, Doctora en Filosofía, docente en la Facultad de Derecho, así como en otras universidades; laboró hasta el año 2013 en la UNIFÉ.

- Sylvia Torres Morales, Abogada por la Universidad de Lima, docente en la Facultad de Derecho; fue Jefa del Departamento de Ciencias Jurídicas; laboró hasta julio de 2014.

- Gloria Benavides Vía, Educadora, Doctora en Educación, past decana de la Facultad de Educación de la UNIFÉ. 
- Ronald Cárdenas Krenz; Abogado por la Universidad de Lima. Past Decano de la Facultad de Derecho de la UNIFÉ. Profesor de las Facultades de Derecho de la UNIFÉ, Lima y ESAN. Ex Superintendente de la SUNARP, Presidente del Consejo del Notariado y Presidente del Consejo Nacional de Catastro. Socio de CDGM Consultores. Experto en temas liberales de la fundación alemana Friedrich Naumann. Incluido en la lista de Who's who in Ethics de la UNESCO. Autor de diversas publicaciones. Past Decano de la Facultad de Derecho de la UNIFÉ. Especialista en temas Bioéticos y Biojurídicos.

- Olga María Castro Pérez Treviño; Abogada por la PUCP, especialista en Derecho de Familia, docente en la Facultad de Derecho de la UNIFÉ y en otras universidades. Magíster en Derecho Civil con mención en Familia por la UNIFÉ. Conciliadora extrajudicial. Miembro de la Comisión Consultiva de la Mujer - Congreso de la República. Autora de diferentes publicaciones de la especialidad

- Maria Teresa Cornejo Fava; Abogada por la PUCP. Con estudios de maestría en Derecho Civil y Comercial. Estudios de Doctorado en Derecho y Ciencias Políticas. Investigadora, autora de libros y artículos en temas de Familia y Sucesiones. Miembro de comisiones revisoras y reformadoras del ordenamiento jurídico peruano vinculadas con el derecho de familia y con el derecho de niños, niñas y adolescentes.

- Nita Gamio Ferreyros: Abogada y Diplomática de carrera. Embajadora de la República. Fue Jefa de la Oficina de Registros Públicos y Miembro del Consejo Asesor del Instituto de la Familia de la UNIFÉ. Integró la Comisión Organizadora de la Facultad de Derecho de la UNIFÉ. Especialista en Derecho de Familia

- Patrick Wagner Grau. Doctor en Filosofía. Doctor en Medicina con especialidad en Nefrología. Miembro de Número de la Academia Nacional de Medicina. Bioeticista. Ha sido Decano del Colegio Médico del Perú. Expositor en eventos nacionales e internacionales.

Asimismo, debemos mencionar y agradecer a aquellas personas que en su condición de Decanos de la Facultad de Derecho participaron activamente durante sus respectivos periodos, en la marcha del Instituto de la Familia y 
que con sus propuestas y apoyo incondicional, contribuyeron al crecimiento del Instituto, así como al cumplimiento de sus objetivos trazados. Gracias Dr. Luis Felipe Almenara Bryson y Mg. Manuel Rivera Parreño.

De igual modo, es importante resaltar que los miembros del Consejo Asesor ejercieron, a lo largo de los años, diversas funciones dentro del Instituto. Es así que, mediante Resolución $\mathrm{N}^{\circ}$ 035-2004-FD-D, expedida por el Decano (a.i.) de la Facultad de Derecho, Dr. Luis Felipe Almenara Bryson, se designó a la Mg. Olga María Castro Pérez-Treviño como coordinadora de las áreas de Investigación, Docencia, Servicio de Asesoramiento y Colaboración del Instituto de la Familia; asimismo, en la misma resolución se designó a la Abog. Maria Teresa Cornejo Fava como coordinadora del Área de Orientación y Promoción Axiológica de la Familia y Difusión, función que posteriormente, fue asumida por la Dra. Myriam Falla Guirao, mediante Resolución $\mathrm{N}^{\circ}$ 042-2005-FD-D

Posteriormente, en vista de la necesidad del apoyo en las actividades administrativas del Instituto, en sesión del Consejo Asesor del Instituto de la Familia de fecha 24 de octubre del año 2006, siendo el Dr. Luis Felipe Almenara Bryson, Decano (a.i.) de la Facultad de Derecho, se acordó proponer y designar a la Abogada Gisela Hortencia Vidal Cabeza como encargada de los asuntos administrativos del Instituto de la Familia de la Facultad de Derecho de la UNIFÉ. Designación que fue puesto a conocimiento del Consejo Universitario mediante Oficio n 606-2006 - UNIFÉ-FD-D.

Años más tarde, el Consejo de Facultad de Derecho en sesión $N^{\circ} 250$, de fecha 5 de agosto de 2014, aprobó el Reglamento del Instituto de la Familia y en virtud a lo establecido en su artículo $4^{\circ}$, debía de nombrarse a la Presidenta del Instituto, así como su coordinadora administrativa. Es así que, mediante Resolución N 073-2014-UNIFÉ-FD-D, siendo Decano (a.i) de la Facultad de Derecho, Mario Romero Antola, se designó a la Abog. María Teresa Cornejo Fava como Presidenta del Instituto de la Familia para el periodo 2014 - 2015, y a la Abog. Gisela Vidal Cabeza como Coordinadora Administrativa del Instituto.

\section{De la acción a la reglamentación}

No cabe duda que las ansias de poder hacer algo para remediar los problemas que aquejan al Derecho de Familia y el Derecho de Personas, 
impulsaron al Instituto a realizar sus actividades basándose en la estructura planteada en el proyecto de creación aprobado por Asamblea Universitaria. En ese sentido, la Coordinadora del Instituto de la Familia, Gisela Vidal Cabeza, en compañía del Derecho (a.i) de la Facultad de Derecho, Mario Romero Antola y de la Presidenta del Instituto Maria Teresa Cornejo Fava, expuso en sesión del Consejo Universitario todas aquellas actividades y acciones realizadas por el Instituto de la Familia en los últimos años, así como también los planes y proyectos por realizar, entre las cuales estaba la elaboración del Reglamento del Instituto de la Familia. La exposición dada mereció la felicitación de los miembros del Consejo Universitario expresado en la Resolución Rectoral $N^{\circ} 231$-2014-CU, felicitando también a los miembros del Consejo Asesor del Instituto de la Familia "por el excelente trabajo que realizan en la defensa y preservación de la Familia" ${ }^{\prime 2}$. Cabe resaltar, que toda la experiencia adquirida en los últimos años en el manejo y gestión del Instituto sirvieron de base para la formulación del Reglamento correspondiente. Es así que, en el mes de agosto del presente año, bajo el Decanato del Dr. Mario Romero Antola, los miembros del Consejo Asesor del Instituto de la Familia, procedieron a elaborar el proyecto de Reglamento, en base a la experiencia de los años de trabajo del Instituto, el mismo que mantuvo la esencia misma de su proyecto de creación. Dicho proyecto de Reglamento fue aprobado por el Consejo de Facultad de Derecho en su sesión $\mathrm{N}^{\circ} 250$ de fecha 5 de agosto de 2014 y presentado al Consejo Universitario para su aprobación.

El Proyecto de Reglamento del Instituto de la Familia contempla en su artículo $1^{\circ}$ su naturaleza, en los términos siguientes:

Artículo $1^{\circ}$.- El Instituto de la Familia de la Facultad de Derecho de la Universidad Femenina del Sagrado Corazón (UNIFÉ) es un órgano de apoyo académico y de investigación que tiene como finalidad contribuir al estudio y solución de la problemática de la familia y fortalecer el matrimonio mediante la promoción y difusión de los valores individuales y sociales del ser humano, la familia y la unión conyugal; así como promover $y$ desarrollar acciones e investigaciones científicas interdisciplinarias, realizando actividades de difusión y promoción académica, y apoyando a la docencia en temas de familia así como bioéticos y biojurídicos.

Asimismo, el Artículo $2^{\circ}$ del citado proyecto de Reglamento, señala que son fines del Instituto los siguientes:

$\overline{2_{\text {Resolucion Rectoral No 231-2014-CU. }} .}$ 
1. Promover y fortalecer los valores individuales y sociales del ser humano, así como los valores que sustentan la institución de la familia, la defensa de los derechos de sus integrantes y del matrimonio.

2. Analizar interdisciplinariamente la problemática de la familia, desde una perspectiva de carácter preventivo, terapéutico y conciliatorio.

3. Contribuir al esclarecimiento y solución de los problemas especificos que se presentan en el seno de las familias, que requieran el apoyo y la asistencia especializadadel Instituto.

4. Estudiar, analizar y contribuir a la solución de los problemas actuales sobre bioética y biojurídica.

5. Desarrollar programas de orientación familiar para las personas que deseen formar una familia y para los que la tengan constituida, propiciando la celebración del matrimonio.

6. Apoyar y asesorar a personas naturales o jurídicas, así como a otros grupos sociales cuya finalidad es la protección de la familia y el matrimonio, brindando servicios de consultoria.

7. Promover, coordinar, realizar estudios e investigaciones sobre asuntos de familia y otras áreas complementarias, desde una perspectiva interdisciplinaria y desde una visión de valores y principios humanos, dentro de los lineamientos del Estatuto de la Universidad Femenina del Sagrado Corazón (UNIFÉ).

8. Investigar y estudiar la realidad de la familia peruana promoviendo su consolidación, propiciando la defensa de la misma y de sus integrantes, así como el fortalecimien to del matrimonio.

9. Fomentar la vocación de profesores(as), alumnas y egresadas por la investigación y la docencia en el área de familia, así como de la bioética y biojurídica, en condiciones adecuadas para lograr la excelencia académica.

10. Establecer vínculos académicos e intercambio científico con otros institutos similares del país y del extranjero.

11. Difundir los resultados de las investigaciones y de las distintas actividades académicas realizadas, por medio de publicaciones periódicas o eventuales. 
12. Fomentar, organizar y realizar eventos sobre la realidad familiar, conyugal y temas afines; así como temas de bioética y biojurídica.

13. Todas aquellas acciones que de una $u$ otra forma se encuentren relacionadas con los fines anteriormente mencionados y se identifiquen con los fines de la universidad.

En cuanto a su organización, el Proyecto de Reglamento mantuvo en principio la misma organización del Instituto propuesto en el Proyecto de creación (Decano, Consejo Asesor); añadiendo otros tal como se señala en su artículo $4^{\circ}$ que establece quienes forman parte del Instituto de la Familia .

\section{El Decano.}

\section{El (la) Presidente(a) del Instituto.}

3. El Consejo Asesor, el mismo que estará integrado por: a) Los docentes de la Facultad de Derecho de la UNIFÉ y Maestría que designe el Decanato, y especialistas en Familia, Bioética y Biojurídica; b) Un representante de la Facultad de Psicología y Humanidades de la Universidad Femenina del Sagrado Corazón (UNIFÉ); c) Un representante de la Facultad de Ciencias de la Educación de la Universidad Femenina del Sagrado Corazón (UNIFÉ); d) Un representante de la Facultad de Ingeniería, Nutrición y Administración de la Universidad Femenina del Sagrado Corazón(UNIFÉ).

4. Los Comités de Áreas: El Instituto cuenta con cuatro Comités Área que estarán bajo la autoridad y supervisión del(a) Presidente(a) denominadas:
a. Comité del Área de Familia y Mujer
b. Comité del Área de los Niños y Adolescentes
c. Comité del Área del Adulto Mayor
d. Comité del Área de Bioética y Biojurídica

Asimismo, cada Comité de Área está a cargo de una persona calificada en el tema y estará integrado por docentes de la UNIFÉ, pudiendo colaborar en él, alumnas y egresadas de la Universidad.

A la fecha, se ha convocado a docentes y estudiantes para conformar los respectivos comités de área y empezar con el desarrollo de los proyectos de investigación. 
5. Miembros Honorarios: Según el Artículo $18^{\circ}$ del Proyecto de Reglamento, son miembros Honorarios del Instituto de la Familia, aquellas personas naturales o jurídicas, que por su destacada trayectoria, apoyo e identificación con los fines del Instituto son reconocidos como tales a propuesta del (a) Decano (a), por cualquiera de los miembros integrantes del Consejo Asesor del Instituto o miembro de Comité de Área.

Para este año 2014 varios ilustres abogados han sido propuestos e incorporados en ceremonia académica como miembros honorarios del Instituto de la Familia como el Dr. Mario Castillo Freyre, Dr. Carlos Fernández Sessarego, y Dr. Fernando Vidal Ramírez.

\section{Razones que respaldan el funcionamiento del Instituto de la Familia:}

1. Por sus objetivos y su naturaleza misma, el Instituto de la Familia es una unidad creada para la investigación, un espacio para la discusión sobre temas de familia, la defensa de la vida, de la persona, temas de importancia para una universidad que sigue y defiende los valores católicos. La contribución en el campo legal por medio de los estudios, e informes legales, así como su contribución en el campo social mediante la atención en consultoría jurídica gratuita, capacitación, es invalorable.

2. Es necesaria una entidad que fortalezca la capacitación en el ámbito del Derecho de Familia, Derecho de las personas, así como la Bioética y Biojurídica.

3. El Instituto de la Familia, ha contribuido en presentar a la sociedad peruana cursos en Derecho de Familia, sobre la niñez y la adolescencia, campo del Derecho que poco había sido abordado para la discusión y capacitación jurídica. Actualmente, saludamos con beneplácito a las entidades que organizan eventos y cursos similares a los organizados por el Instituto.

4. Las actividades del Instituto han contribuido que varias personas se interesen por llevar también la Maestría en Derecho Civil con mención en Familia, especialidad a la cual recurren principalmente abogados, jueces y fiscales para el perfeccionamiento de su especialidad. 


\section{A manera de Conclusión:}

Finalmente, somos conscientes que nos depara mucho trabajo por realizar, y esperamos contar con el apoyo de todos aquellos que persigan los mismos ideales y se identifiquen con los fines del Instituto de la Familia. Sabemos que los problemas que aquejan a la familia y a la persona no son fáciles de combatir, pero deseamos compartir esta responsabilidad también con otros, toda vez que todos provenimos de una familia y anhelamos que su situación de crisis cambie para el bien de las próximas generaciones. La defensa de la familia y de la persona será siempre nuestro norte, y nuestra preocupación; por ello, deseamos contagiar nuestro entusiasmo a muchos más. En tal sentido, resultan sumamente significativas las siguientes palabras que dijera el Papa Francisco en su discurso dirigido a los obispo de Sri Lanka, el 5 de mayo del presente año: "Cuando nos preocupamos por nuestras familias y sus necesidades, cuando entendemos sus problemas y esperanzas, (...) cuando sostienen a la familia, sus esfuerzos repercuten no sólo en beneficio de la Iglesia; también ayudan a la entera sociedad". Dejemos una huella de bien en nuestra sociedad. Bienvenidos. Para cualquier informacion puedes recurrir a nuestra página en Facebook https://www.facebook.com/ ifamiliaunife o escribir al correo electrónico: ifamilia@unife.edu.pe

\section{Referencias:}

- Proyecto de creación del Instituto de la Familia.

- Resolución Rectoral N 105-2000-CU defecha 14 de junio de 2000.

- Copia del Acta de Asamblea Universitaria Extraordinaria de fecha 24 de febrero de 2001.

- Resolución N035-2004-FD-D, de fecha 23 de abril de 2004.

- Resolución Rectoral No 231-2014-CU.

- Resolución N073-2014-UNIFE-FD-D.

- Acta del Consejo Asesor del Instituto de la Familia, de fecha 24 de octubre del año 2006.

- Acuerdo del Consejo Universitario Sesión N N$^{\circ} 541$ de fecha 14 de junio de 2000.

- Resolución No. 042-2005-FD, de fecha 27 de abril de 2005. 
